\title{
Lightweight mid-infrared methane sensor for unmanned aerial systems
}

\author{
Levi M. Golston ${ }^{1,2} \cdot$ Lei Tao $^{1,2,3} \cdot$ Caroline Brosy $^{4} \cdot$ Klaus Schäfer $^{4} \cdot$ Benjamin Wolf $^{4}$ • \\ James McSpiritt ${ }^{1,2} \cdot$ Bernhard Buchholz $^{1,5}$ - Dana R. Caulton ${ }^{1,2} \cdot$ Da Pan ${ }^{1,2}$. \\ Mark A. Zondlo ${ }^{1,2} \cdot$ David Yoel $^{6} \cdot$ Harald Kunstmann $^{4} \cdot$ Marty McGregor $^{6}$
}

Received: 31 January 2017 / Accepted: 19 April 2017 / Published online: 19 May 2017

(C) The Author(s) 2017. This article is an open access publication

\begin{abstract}
The design and field performance of a compact diode laser-based instrument for measuring methane on unmanned aerial systems (UAS) is described. The system is based on open-path, wavelength modulation spectroscopy with a $3.27 \mu \mathrm{m} \mathrm{GaSb}$ laser. We design two versions of the sensor for a long-endurance fixed wing UAS and a rotary wing hexacopter, with instrument masses of 4.6 and $1.6 \mathrm{~kg}$, respectively. The long-endurance platform was used to measure vertical profiles of methane up to $600 \mathrm{~m}$ in altitude and showed repeatability of 13 ppbv between multiple profiles. Additionally, the hexacopter system was used to evaluate the evolution of methane in the nocturnal boundary layer during the ScaleX field campaign in Germany, where measured data is consistent with supporting ground-based methane and meteorological measurements.
\end{abstract}

This article is part of the topical collection "Field Laser Applications in Industry and Research" guest edited by Francesco D'Amato, Erik Kerstel, and Alan Fried.

Mark A. Zondlo

mzondlo@princeton.edu

1 Department of Civil and Environmental Engineering, Princeton University, Princeton, NJ 08544, USA

2 Center for Mid-InfraRed Technologies for Health and the Environment, NSF-ERC, Princeton, NJ 08540, USA

3 Present Address: Intelligent Material Solutions, Inc., Princeton, NJ 08540, USA

4 Karlsruhe Institute of Technology, Campus Alpin, Institute of Meteorology and Climate Research (IMK-IFU), 82467 Garmisch-Partenkirchen, Germany

5 Present Address: Physikalisch-Technische Bundesanstalt Braunschweig, Brunswick, Germany

6 American Aerospace Technologies, Inc., Conshohocken, PA 19428, USA
Testing results on both platforms demonstrated our lightweight methane sensor had an in-flight precision of 5-10 ppbv $\mathrm{Hz}^{-1 / 2}$.

\section{Introduction}

Methane is a strong greenhouse gas and plays a key role in determining the climate impact of sources such as wetlands, livestock, and oil and gas equipment [1-3]. There is a continuing need for technology to better understand and track the sources and sinks of methane at the local scale. Unmanned aerial systems (UAS) are attractive platforms for such measurements due to their flexibility and autonomous nature. In particular, small $(<25 \mathrm{~kg})$ UAS have low operation costs, relaxed regulatory requirements, and can operate near the surface, where most emissions originate. As an example, a near-infrared sensor (100 ppbv precision) equipped on a remote-controlled helicopter has been used to estimate the magnitude and temporal variability of methane emissions from a natural gas compressor station [4], and serves as an alternative to mobile laboratory and ground survey techniques which are more time-consuming or may miss elevated leak sources.

To leverage the potential of UAS, there is a need for high performance trace gas sensors meeting the payload constraints of typical fixed wing and copter platforms, including for methane [5]. Due in part to this gap, air quality and trace gas monitoring with UAS is still a relatively new area of research. Methane instruments are available that have excellent performance, but are generally designed for aircraft- [6] or ground-based applications [7] where size, power consumption and mass are not significantly restricted. A sensor based on integrated cavity output spectroscopy (ICOS) technology from Los Gatos Research 
weighing $19.5 \mathrm{~kg}$ has been flown on the NASA SIERRA UAS platform [8], which like many long-endurance UAS has a large payload capacity. More compact methane sensors are available that typically either use standoff detection for path integrated measurements $[9,10]$, or have been targeted at high concentrations such as for direct sampling from natural gas leaks. In addition, several lightweight in situ methane sensors have previously been demonstrated for high-altitude balloon-borne or small UAS use $[4,11,12]$. These employed an open-path design, where air flows directly into the optical cell rather than using sampling equipment allowing for low weight and inherently high time response [7]. However, each used near-infrared laser sources, so a further improvement in performance and weight is expected using a mid-infrared laser probing methane's strong fundamental absorption band in the $3.3 \mu \mathrm{m}$ region. A notable lightweight, mid-infrared system is the Tunable Laser Spectrometer, which has been used to constrain the possible levels of methane on Mars [13, 14].

We demonstrate for the first time a lightweight, midinfrared, in situ methane sensor that was modified to operate on two different UAS platforms. The sensor employs open-path wavelength modulation spectroscopy (WMS) for sensitive detection of methane in the atmosphere. The first platform, a long-endurance fixed-wing UAS, had modest payload constraints and allowed us to test precision and stability on a multi-hour flight. The hexacopter system required additional reductions in mass and operates with much shorter flight times, but was well-suited for a nocturnal boundary layer application $[15,16]$, where methane accumulates in the stable, shallow layer near the surface. The sensor's precision of 5-10 ppbv was adequate to resolve vertical gradients of atmospheric background methane ( 2 ppmv) in both day- and night-time conditions, and meets previously estimated criteria of $<40 \mathrm{ppbv}$ needed to quantify emissions at a landfill [5], which may produce enhancements of 100-1000 s ppbv above the background level. The combination of both large, long-endurance, and small, flexible platforms allows for a variety of applications for probing the atmospheric boundary layer.

\section{Design and methods}

\subsection{Description of instrument for both configurations}

The common attributes of the sensor on both platforms are the core optical cell and most of the electronics components. The optical cell housing was fabricated using 3D printed ABS with spacing and rigidity maintained by three $8 \mathrm{~mm}$ hollow carbon fiber rods. A Herriott cell [17] was chosen due to its well-established stability in field environments and compact geometry, with an $11.2 \mathrm{~cm}$ base path and $2.7 \mathrm{~m}$ optical path length ( $N=24$ passes) confined by $\varnothing(5.08 \mathrm{~cm})$ gold-coated mirrors. As an open-path design, air moves directly through the optical cell based on atmospheric motions relative to the platform movement rather than using a pump. The laser and detector were attached to opposite sides of the cell and aligned using additional steering mirrors. We employed a GaSb distributed feedback (DFB) laser (Norcada), a LDTC0520 laser temperature and current controller (Wavelength Electronics), and an optically immersed $\mathrm{HgCdTe}$ photodetector with an AC coupled preamplifier (Vigo). A single board computer (Advantech) and PCIe-6251 data acquisition board (National Instruments) were dedicated to system control and data processing. Finally, a BMP180 sensor (Bosch) was situated at the edge of the electronics box to measure barometric pressure. While these aspects are the same for both configurations, details of the electronics box and mounting differed due to integration and flight operation needs.

\subsubsection{Long-endurance system}

The platform that formed the basis of the long-range design was an American Aerospace Technologies, Inc. (AATI) RS-20. The RS-20 has a payload of $25 \mathrm{~kg}$, flight times of up to $16 \mathrm{~h}$, and a maximum speed of $46.3 \mathrm{~m} \mathrm{~s}^{-1}$. Specific to this UAS, the electronics and sensor were designed to mount underneath one wing of the RS-20, enabled by its ability to take off with an asymmetric load. DC power and an Ethernet link for real-time communications were connected through the wing to the UAS fuselage. The sensor electronics were enclosed in a $20 \mathrm{~cm} \times 26 \mathrm{~cm} \times 11 \mathrm{~cm}$ solid aluminum case and placed behind the optical cell relative to the flow of air during flight (Fig. 1a), with both components mounted on an aluminum plate connecting to a hard point on the wing. The overall mounting scheme was designed to ensure air-readiness and to withstand the pneumatic launch that produces forces of up to 10-g. Altitude was estimated using barometric pressure from the BMP180.

\subsubsection{Hexacopter system}

The hexacopter platform that formed the basis of this configuration was a Pro X-3 Lite by Stein Elektronik (Fig. 1b). This medium lift hexacopter has a $2.1 \mathrm{~kg}$ payload capacity remaining after flight battery and a 5-6 min flight duration with a take-off weight of $4.9 \mathrm{~kg}$. The platform necessitated a further reduction in sensor mass to meet these constraints, which was achieved with a lighter, plastic electronics box and a smaller optical cell housing. The hexacopter was operated using a Pixhawk controller and the ArduPilot Copter 3.3 software to program flight patterns and access telemetry data. Here the sensor was powered by its own 

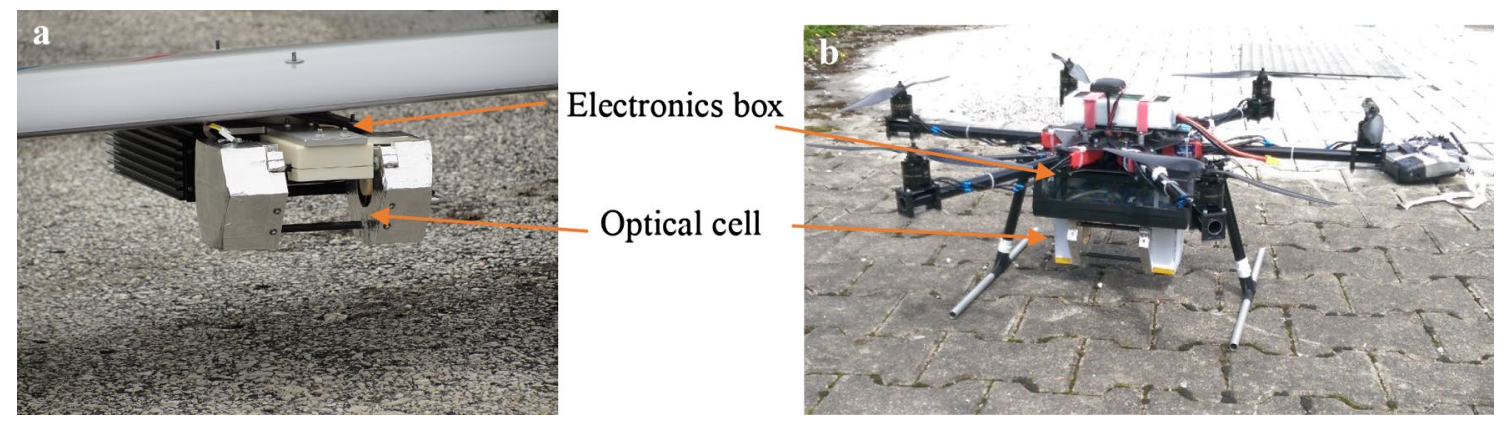

Fig. 1 Picture of sensor installed on its measurement platform in a fixed-wing UAS configuration and b hexacopter configuration

Table 1 Summary of sensor specifications in both configurations

\begin{tabular}{lll}
\hline Parameter & Long-range sensor & Hexacopter sensor \\
\hline Precision & $5 \mathrm{ppbv} \mathrm{Hz}{ }^{-1 / 2}$ & $10 \mathrm{ppb} \mathrm{Hz}^{-1 / 2}$ \\
Mass & $0.68 \mathrm{~kg}$ (sensor head) & $1.45 \mathrm{~kg}$ (sensor head and control box) \\
& $4.00 \mathrm{~kg}($ control box) & $0.14 \mathrm{~kg}$ (battery) \\
Dimensions & $24 \mathrm{~cm} \times 10 \mathrm{~cm} \times 10 \mathrm{~cm}$ (sensor head ) & $25 \mathrm{~cm} \times 16 \mathrm{~cm} \times 18 \mathrm{~cm}$ \\
& $20 \mathrm{~cm} \times 26 \mathrm{~cm} \times 11 \mathrm{~cm}$ (control box) & \\
Frequency & $1-10 \mathrm{~Hz}$ & \\
Power & $30 \mathrm{~W}$ & \\
Principle & Open-path WMS & \\
\hline
\end{tabular}

$0.14 \mathrm{~kg}, 1300 \mathrm{mAh}$ 4-cell LiPo battery. The detector controller was updated from STCC-04 (Vigo) to the newer PTCC-01-OEM, which has a smaller form factor. The overall specifications of the methane sensor as deployed on both platforms are shown (Table 1).

For the hexacopter system, an Innovative Sensor Technology HYT 271 was added directly outside of the multipass cell to measure the ambient temperature and humidity. This is based on a proportional to absolute temperature (PTAT) measurement and capacitive polymer relative humidity measurement. Altitude and position were obtained from the hexacopter's flight control, which incorporates both pressure and GPS information.

\subsection{Spectroscopy and data processing}

The laser is tuned over a $1.2 \mathrm{~cm}^{-1}$ region centered at $3057.4 \mathrm{~cm}^{-1}$ containing strong absorption features for both methane and water vapor (Fig. 2). The water vapor feature is composed of one dominant line, while methane is a composite of three lines $\left[S=2.106 \times 10^{-19}\right.$, $1.26 \times 10^{-19}, 1.26 \times 10^{-19} \mathrm{~cm}^{-1} /\left(\right.$ molecule $\left.\left.\mathrm{cm}^{-2}\right)\right][18]$ that are broadened at atmospheric pressure. A $200 \mathrm{~Hz}$ sawtooth ramp was applied with additional $20 \mathrm{kHz}$ sinusoidal modulation to control laser drive current. Increasing the ramp and modulation rates is advantageous for increasing signal-to-noise but is limited by the ability to tune fully over the water and methane

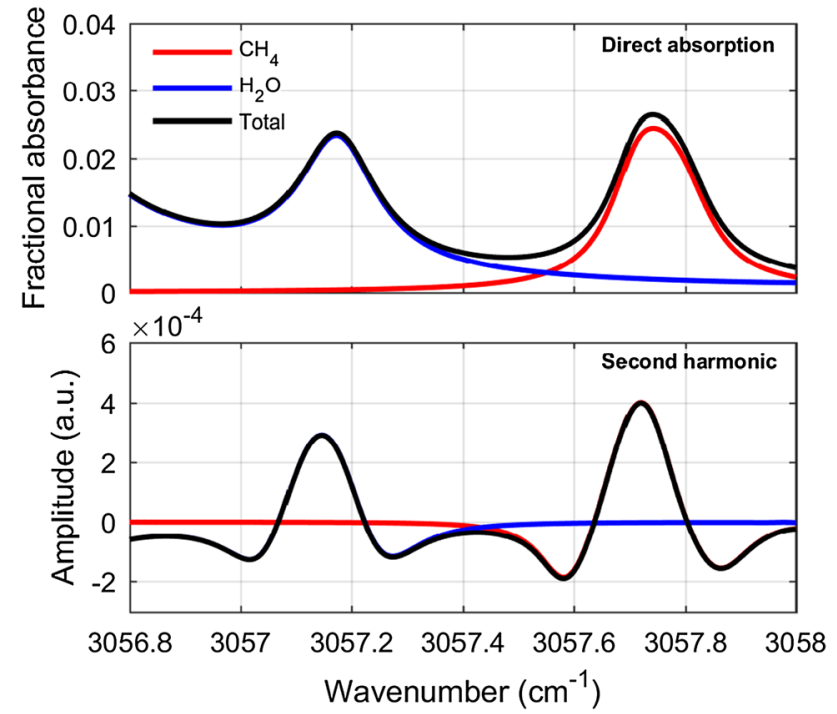

Fig. 2 Simulated direct absorption and second harmonic spectra including the methane and water vapor absorption features under ambient conditions $\left(1013 \mathrm{hPa}, 296 \mathrm{~K}, 1 \% \mathrm{H}_{2} \mathrm{O}, 2 \mathrm{ppmv} \mathrm{CH}_{4}\right)$

features. Data were averaged and logged at $20 \mathrm{~Hz}$ for the fixed-wing configuration and $10 \mathrm{~Hz}$ for the hexacopter configuration.

The harmonic signals were generated in real-time using a LabVIEW-based lock-in detection scheme [19] with methane and water vapor concentrations retrieved 
using a second harmonic ( $2 f$ ) peak-to-trough height calculation normalized by the first harmonic $(1 f)$ at the peak centers to account for intensity variations. The $2 f / 1 f$ values were calibrated either by placing the whole sensor in an enclosed box and flowing calibration standards or with comparison to reference instruments, as described in Sect. 2.3. In both cases, a two-point calibration approach was used with a zero and linear slope.

In post processing, methane and supporting data were time synchronized to the GPS time and location information at $1 \mathrm{~Hz}$. An internal GPS was used for the fixed-wing system, while for the hexacopter the copter GPS was used to avoid the need for an additional antenna. Data with low signal strength (defined as detector voltage $<0.2 \mathrm{~V}$ ) were then excluded to remove incidences where the beam was blocked. To account for pressure effects a correction function, $\kappa(P)$ is applied [7], which was derived based on simulations using HITRAN 2012 data [18] to account for spectroscopic and density (ideal gas law) effects defined relative to standard conditions $(296 \mathrm{~K}, 1013 \mathrm{hPa})$. This correction additionally accounts for the fact that a constant modulation amplitude was used, leading to changes in the modulation index and the shape of the $2 f$ signal. For the fixedwing configuration, temperature measurements were not available in-flight and a ground-based, fixed station was used. For the flight altitude envelope of $600 \mathrm{~m}$ during midday, the expected change in temperature is expected to be 3-6 K colder than the surface based upon environmental/ adiabatic lapse rates. This temperature decrease results in an increase in the $\mathrm{CH}_{4}$ concentrations (i.e., absorption) by $1-1.5 \%$ from the ideal gas law and a decrease in absorption from the linestrength of $1-1.5 \%$. In combination, these effects nearly cancel out and thus the overall uncertainty in the absolute concentration from ignoring temperature is negligible compared to instrument noise (5-10 ppbv).

An additional limitation was that active line locking (stabilization of the laser tuning) was not used, so the methane concentration was prone to drift if there were changes in the peak position. This was primarily an issue for the hexacopter flights, which were short in duration and had more rapidly varying environmental conditions than with the fixed-wing configuration. This was accounted for using a polynomial to correct for changes to the extent that drift in concentration was correlated with peak position. Individual hexacopter flights were excluded if peak position drifted outside of the preset window used by the single board computer for calculation of peak-to-trough heights.

A final aspect to the approach was inclusion of an inline reference-cell containing the target gas (methane) at reduced pressure. This is a new variation on previous use of in-line reference cells which have targeted a separate gas that is spectrally non-overlapping or distinguishable using higher harmonics $[19,20]$. Here the in-line reference cell was $2 \mathrm{~cm}$ long and contained $0.4 \%$ methane in $\mathrm{N}_{2}$ at 30 Torr, which can be effectively measured using direct absorption spectroscopy (DAS). The signal can be extracted using a time-multiplexed scheme where there are both scans with and without sinusoidal modulation every second [21]. A duty cycle of 19:1 modulated to non-modulated scans was used, so the sensor was predominately aimed at WMS, while the hexacopter system ran in fully WMS mode since the reference cell had lost pressure. The parameters were optimized so that the direct absorption current offset was increased slightly, but not so much as to cause laser instability. Experimental spectra will be discussed in Sect. 3.1.

\subsection{Field deployments}

\subsubsection{Long-endurance UAS}

Both systems were deployed for field testing and measurements of methane mixing ratios in the lower atmosphere. Fixed-wing UAS flights were conducted on September 9, 2015 and February 24-25, 2016 operated out of the Cape May Airport, a Federal Aviation Administration (FAA) UAS test site in southern New Jersey. The first flight encompassed a $12 \times 15 \mathrm{~km}$ area over the nearby coastline (Fig. 3a) and is the focus of our analysis here. The sensor was calibrated beforehand using nitrogen as a zero and a span gas of 2.045 ppmv methane (GTS-Welco $2.12 \pm 5 \%$ ppmv methane in air, cross-calibrated against a NOAA standard to $2.045 \mathrm{ppmv} \pm 1 \%$ using a LI-COR LI-7700). A second flight was flown on February 24 but there were difficulties with wireless communication and the sensor's internal computer restarting. On February 25, a controlled methane release was conducted, with the UAS making downwind passes at the Cape May Airport. Analysis of the data did not see a methane enhancement from the release since wind meteorological conditions were not favorable. Information from a 3D sonic anemometer was used with WindTrax (http://www.thunderbeachscientific.com) to model the release, which also supported that an observable enhancement would not be expected above $50 \mathrm{~m}$.

\subsubsection{Hexacopter}

Flights with the hexacopter system were conducted in July 2016 as part of the ScaleX campaign (http://scalex. imk-ifu.kit.edu) [22], a "scale-crossing" experiment at the Fendt field site within the TERestrial ENvironmental Observatories (TERENO) network [23] in southern Germany. An innovative approach had been employed in ScaleX 2015 where a UAS was equipped with a 

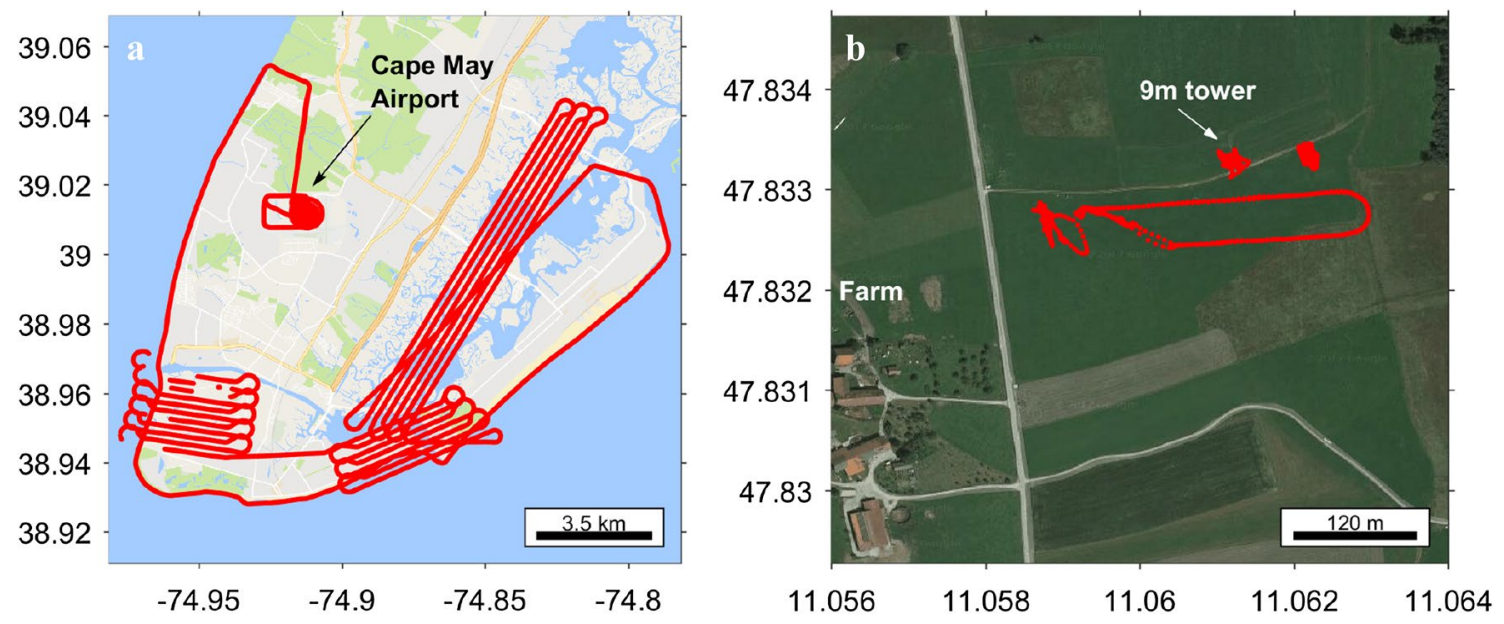

Fig. 3 Flight maps superimposed on satellite imagery for the field experiments in a southern New Jersey, United States on September 9, 2015 and $\mathbf{b}$ around Fendt, Germany. The location of the $9 \mathrm{~m}$ tower equipped with three air inlets and a Picarro methane analyzer is labeled

Teflon drag-tube connected to a Picarro methane analyzer on the ground, where results have been described elsewhere [22]. Here, we use our new sensor to obtain direct, in situ measurements with efforts focused during an intensive observational period from 21:00 to 06:00 (local time) on July 06-07.

Flight tracks are shown at the Fendt field site (Fig. 3b), along with the location of an instrumented $9 \mathrm{~m}$ tower containing air inlets at 1,3 , and $9 \mathrm{~m}$. A gas switching system was used in connection with a Picarro G2508 that measured at these heights sequentially, sampling each height for $2.5 \mathrm{~min}$. A container also located in Fendt (not shown) was equipped with a Los Gatos DLT100 , providing additional long-term information about methane patterns at the site [24].

In total, ten flights were conducted during the UAS intensive observational period, along with five additional daytime flights in Fendt and one at the IMK-IFU on July 18,2016 . One extended ( $2 \mathrm{~h}$ ) intercomparison was conducted on July 11 with the sensor collocated at the Picarro tower's $1 \mathrm{~m}$ inlet. A second intercomparison $(2 \mathrm{~h})$ collocated with the Los Gatos inlet on the roof of a measurement container was conducted on July 17 starting at sunset. Reference gas measurements $\left(\mathrm{CH}_{4}=1893 \pm 1 \%\right.$ ppbv $)$ were made several times during the campaign using a closed chamber, and zero gas measurements were done using nitrogen in a lab at the IMK-IFU campus. A constant linear calibration slope was used throughout campaign, but an offset was obtained by comparison with the Picarro each flight. This was a solution to help account for drifts by comparing to a highly stable ground-based instrument without having to do full re-calibrations in the field.

\section{Results}

\subsection{Fixed-wing based system}

A 30-min section of data obtained while flying over the Cape May region at constant altitude was used as a measure of the sensor precision in the in-flight environment. An Allan-Werle deviation plot [25] with this data shows a precision of $5 \mathrm{ppbv}$ at $1 \mathrm{~Hz}$ (Fig. 4). Short-term results follow the behavior of white noise (slope $\sim 1 / \sqrt{\tau}$ ) while there is a relatively short turn-over time of 10-15 s. By comparison, an experiment in the laboratory while flowing a calibration standard (2.045 ppmv, $1 \%$ uncertainty) found a precision of $4.5 \mathrm{ppbv}$ at $1 \mathrm{~Hz}$, a decrease of only $12 \%$ in the field environment suggesting a robust optomechanical structure and

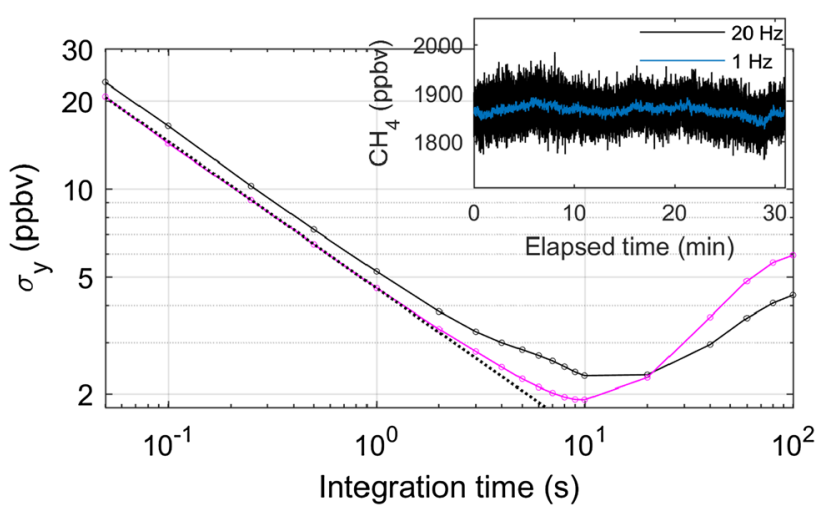

Fig. 4 Allan-Werle deviation experiment with data taken from an extended segment of flight at constant $(600 \mathrm{~m})$ altitude (black), compared to data collected in the laboratory (magenta). The measured time series of mixing ratios corresponding to the in-flight plot is shown as an inset 
insensitivity to the vibrations on this platform. Both experiments also likely included effects from uncontrolled temperature variations and in the field-case, real atmospheric variability in methane when traveling over lateral distances of 10 's of $\mathrm{km}$.

To test stability and reproducibility on a longer timescale, a sequence of six vertical profiles was also obtained over a 15 min time period during the same flight (Fig. 5). Measurements were conducted while making transects along the tidal wetlands between Cape May and Wildwood. The UAS started and ended the measurement sequence at $430 \mathrm{~m}$ and profiled between 120 and $583 \mathrm{~m}$. The atmosphere is generally considered well-mixed (i.e. constant with altitude) in the afternoon boundary layer, but variation is possible at the 10's of ppbv level. Even at the nearby NOAA profiling site located over the Atlantic Ocean $\sim 50 \mathrm{~km}$ SE of Cape May, methane mixing ratios often deviate from flat or decreasing with altitude. The UAS profiles we observed showed measurable structure, with minima at 130 and $400 \mathrm{~m}$ and maxima at 240 and $540 \mathrm{~m}$, indicating that the sensor can resolve atmospheric variability since results were repeatable across multiple up-down profiles. The deviation between profiles $(1 \sigma)$ had a mean of $13 \mathrm{ppbv}$ and was as low as 8 ppbv near $330 \mathrm{~m}$, which is an additional proxy for the upper limit of in-flight precision.

The multiplexed DAS approach provides additional information about the stability of the sensor during this flight. An example of an in-flight non-modulated scan and subsequent processing sequence is shown (Fig. 6). The spectra are averaged and saved at $15 \mathrm{~s}$ interval, but because only 1 in 20 scans are non-modulated, each recorded spectrum represents an integration time of $0.75 \mathrm{~s}$. A fifth order polynomial was used to extract the absorption baseline, calculated from nine fitting points located away from any absorption features. The baseline-subtracted absorption signal of water vapor and methane and the residual between measurement and Voigt line fitting is also shown (Fig. 6).
Fig. 5 Methane data collected during multiple up-down transects over a coastal area in southern New Jersey, including a time series of methane and altitude, $\mathbf{b}$ vertical profile of methane showing repeatable features over the profiling period from $15: 45$ to $16: 00$
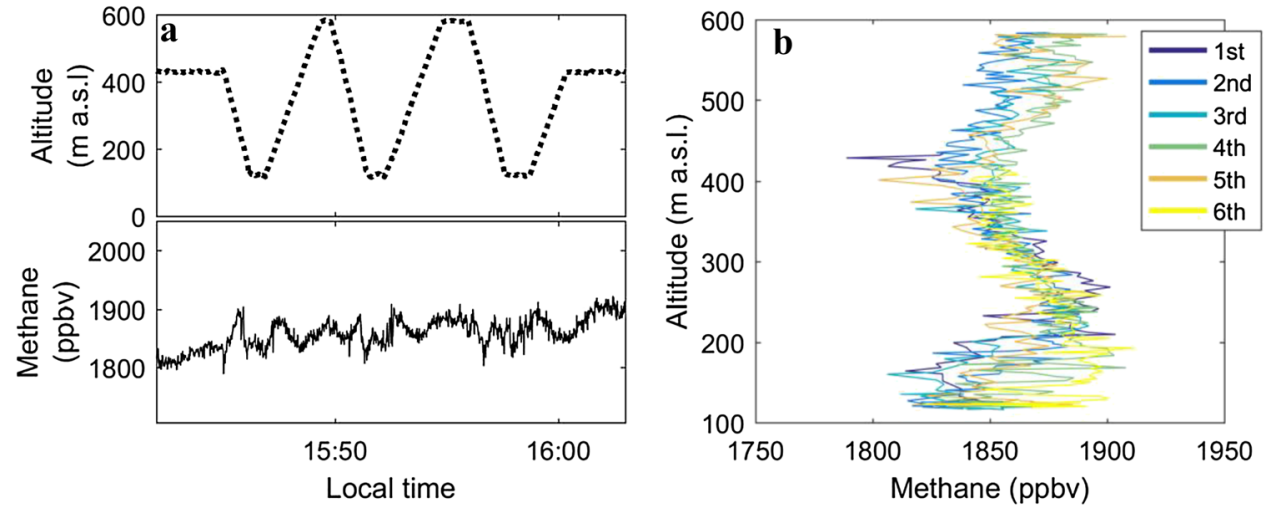

Fig. 6 In-flight result showing a typical saved direct absorption spectra (15 s average, where 1 in every 20 scans is a nonmodulated scan). a Polynomial fitting of the direct absorption baseline. b Difference of the measured signal and the baseline. $\mathbf{c}$ Residual of the fit using Voigt line profiles
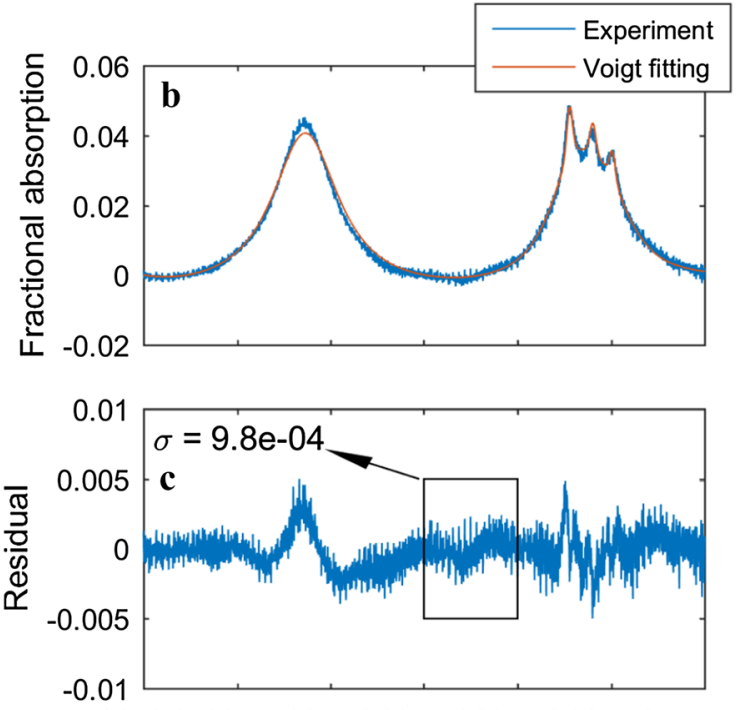

$3056.83057 \quad 3057.23057 .43057 .63057 .8$

Wavenumber $\left(\mathrm{cm}^{-1}\right)$ 
The fit is accomplished using nonlinear least squares to solve for the $\mathrm{CH} 44_{\text {ambient }}, \mathrm{CH} 4_{\text {ref. cell }}$, and $\mathrm{H}_{2} \mathrm{O}$ mixing ratios. Three sharp peaks from the reduced pressure reference cell are clearly visible overlaying the ambient methane feature, which enables it to be retrieved separately from the ambient signal. The standard deviation $(\sigma)$ of the residual was calculated between 3057.4 and $3057.6 \mathrm{~cm}^{-1}$, away from the line centers where the residual may be driven by the accuracy of the Voigt line shape function rather than random noise, was approximately $10^{-3}$. We did not use the ambient methane concentration data directly because of the higher noise compared to WMS, but rather used $\mathrm{CH} 4_{\text {ref. cell }}$ as a continuous proxy short-term instrumental noise.

\subsection{Hexacopter-based system}

Ten night-time flights were taken during ScaleX, while six passed the quality check criteria and are shown as vertical profiles sequenced by the time of night/morning (Fig. 7), excluding the sixth where pressure and temperature were not saved. The red dots show methane mixing ratios binned by altitude, while the trend is illustrated using Gaussian kernel smoothing. We use $2 \mathrm{~m}$ bins since the air is likely mixed below this scale due to the circulation produced by the hexacopter rotors. The downdraft effect on trace gas measurements is an active area of research, but is thought to cause downward mixing of air and may disturb fine-scale features of the profile. The 21:00 profile was well-mixed up to $75 \mathrm{~m}$, consistent with expected results during daytime, and a layer top at $100 \mathrm{~m}$ that was also seen in the temperature profile. The profile at midnight saw a decreasing concentration from ground level up to about $125 \mathrm{~m}$. The remaining profiles take a markedly different shape, likely due to local meteorological conditions. Transport of methane from nearby dairy farms is known to cause enhanced methane [24], with the closest farm located $0.5 \mathrm{~km}$ southwest of the main UAS launch location. The Fendt site is also influenced by a nocturnal low level jet which tend to mix turbulence downwards from aloft [26]. The predominantly northerly wind was seen to shift to southwesterly around 02:00.

The evolution of methane seen by the Picarro-instrumented tower is shown, along with a comparison to the average measurement from the UAS at the equivalent height (Fig. 8). The ground based measurement resolves some of the complexity, with methane greater at the surface than at $9 \mathrm{~m}$ up until 23:00 and after 04:00, but inverted for much of the time in-between. The UAS found consistent results, with small gradients at 21:00 and 0:00 and a larger, inverted gradient at 03:00. Up until 02:30 there was an accumulation seen by the Picarro analyzer. Then the concentration as well as the gradient decreased followed by an again developing strong gradient from 04:00 until 05:15. The gradient at 05:00 from the UAS was consistent in sign but about half the magnitude of the Picarro. This is likely the result of the strong vertical, and likely horizontal, gradient that makes it difficult to directly compare the measurements. Similarly large ( $>100$ ppbv) differences were also sometimes observed between the tower and UAS-drag tube during the ScaleX 2015 campaign [22]. The comparison is also more uncertain where the mixing ratio is changing quickly, since the UAS is measuring over a period of time and the Picarro also only samples at one inlet at a time.

\section{Summary and conclusions}

We demonstrated a compact, open-path methane sensor with measurements conducted on both small and large unmanned aerial systems and which weighed 4.6 and $1.6 \mathrm{~kg}$, respectively. In-flight precision of the fixed-wing
Fig. 7 Five vertical profiles of methane taken overnight in Fendt, Germany, from ground level up to a flight ceiling of $150 \mathrm{~m}$. Data are shown averaged every $2 \mathrm{~m}$ (red dots) as a smoothed profile (blue line), and compared to the measured temperature profile (black dots)
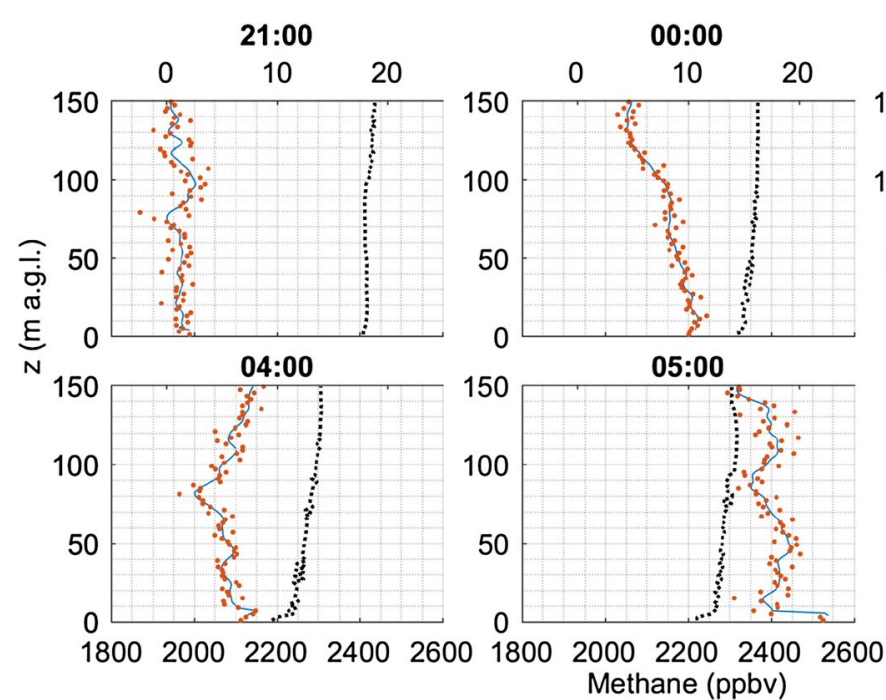

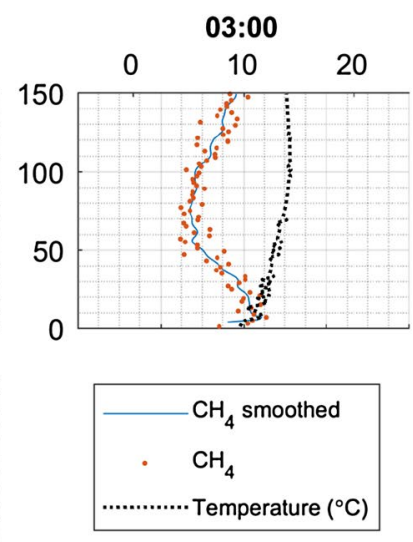


Fig. 8 Methane measurements taken from the tower and from the UAS during the same period as in Fig. 7. The open circles are data measured by the Picarro instrument and connected with lines, with black and blue corresponding to the 1 and $9 \mathrm{~m}$ inlets, respectively. The $3 \mathrm{~m}$ inlet is omitted for clarity and showed similar trends. Cross marks use the same colors and correspond to measurements from the UAS averaged at 1,9 , and $49 \mathrm{~m}$

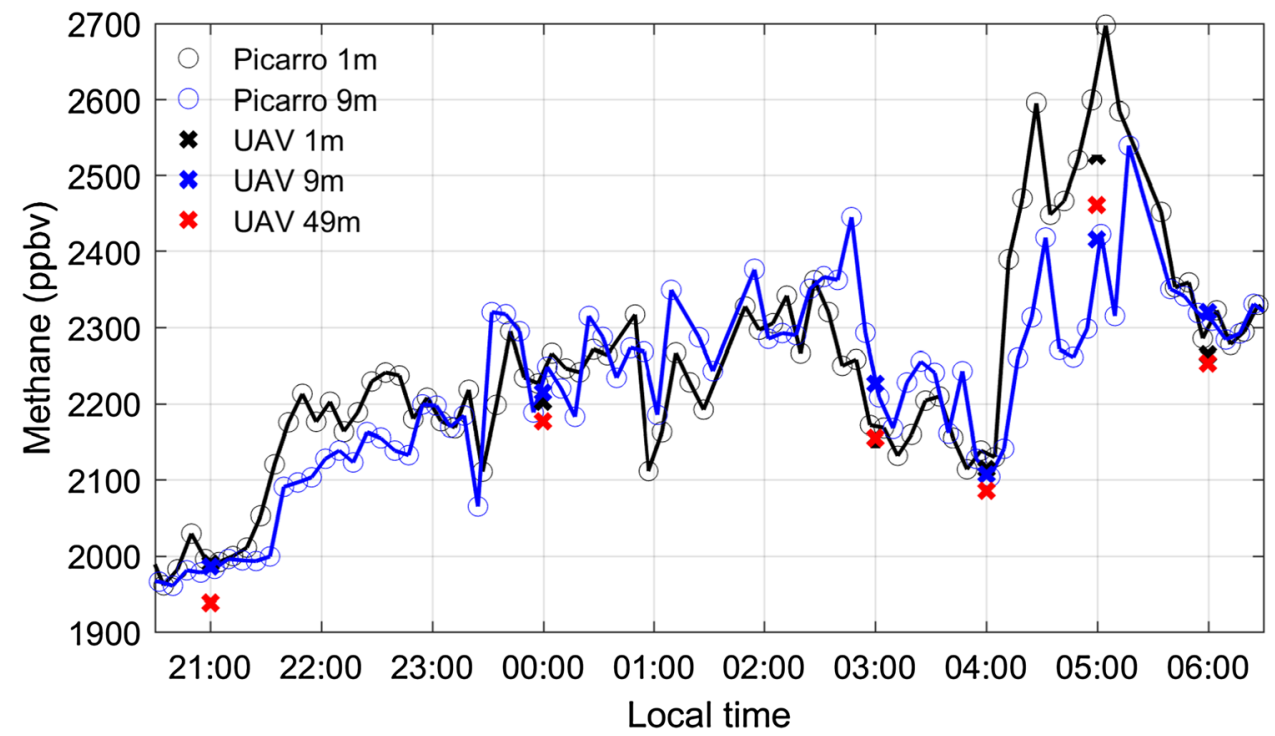

system showed 5 ppbv at $1 \mathrm{~s}$ averaging time while the smaller system achieved $10 \mathrm{ppbv}$ at $1 \mathrm{~s}$ averaging time. Vertical profiles were presented in the daytime over a coastal area up to $600 \mathrm{~m}$ a.g.l. and during night-time at a grassland site in southern Germany. The night-time vertical profiles were compared to available observations from two heights at a $9 \mathrm{~m}$ tower. Additionally, a same-gas reference cell was described providing additional evidence of stability during the flights.

The ability of the sensor to operate on small UAS opens up new opportunities for studies of trace gases in the atmospheric boundary layer, due to their low cost, ability to operate down to ground-level, highly flexible flight patterns, and reduced regulatory scrutiny. The combination of small UAS with a high-precision methane sensor will provide a more-detailed knowledge of vertical and horizontal heterogeneity of methane, as well as applications in localizing and quantifying emission sources. Further work will improve the long-term stability of the sensor to reduce the need for ground-based reference instruments and ruggedize the sensor for repeated field use.

Acknowledgements We thank the staff of IMK-IFU for their support during ScaleX, and NSF IIP:1445031 for funding. The TERrestrial Environmental Observatory (TERENO, http://www.tereno.net) preAlpine infrastructure is funded by the Helmholtz Association and the Federal Ministry of Education and Research. We thank the Scientific Team of ScaleX Campaign 2016 (http://scalex.imk-ifu.kit.edu) for their contribution.

Open Access This article is distributed under the terms of the Creative Commons Attribution 4.0 International License (http://creativecommons.org/licenses/by/4.0/), which permits unrestricted use, distribution, and reproduction in any medium, provided you give appropriate credit to the original author(s) and the source, provide a link to the Creative Commons license, and indicate if changes were made.

\section{References}

1. U.M. Persson, D.J.A. Johansson, C. Cederberg, F. Hedenus, D. Bryngelsson, Environ. Res. Lett. 10, 34005 (2015)

2. R.A. Alvarez, S.W. Pacala, J.J. Winebrake, W.L. Chameides, S.P. Hamburg, Proc. Natl. Acad. Sci. 109, 6435 (2012)

3. G.J. Whiting, J.P. Chanton, Tellus B 53, 521 (2001)

4. B.J. Nathan, L.M. Golston, A.S. O'Brien, K. Ross, W.A. Harrison, L. Tao, D.J. Lary, D.R. Johnson, A.N. Covington, N.N. Clark, M.A. Zondlo, Environ. Sci. Technol. 49, 7896 (2015)

5. G. Allen, J. Pitt, P. Hollingsworth, I. Mead, K. Kabbabe, G. Roberts, C. Percival, Measuring Landfill Methane Emissions Using Unmanned Aerial Systems: Field Trial and Operational Guidance (Bristol, United Kingdom, 2015)

6. J.R. Pitt, M. Le Breton, G. Allen, C.J. Percival, M.W. Gallagher, S.J.-B. Bauguitte, S.J. O'Shea, J.B.A. Muller, M.S. Zahniser, J. Pyle, P.I. Palmer, Atmos. Meas. Tech. 9, 63 (2016)

7. D. McDermitt, G. Burba, L. Xu, T. Anderson, A. Komissarov, B. Riensche, J. Schedlbauer, G. Starr, D. Zona, W. Oechel, S. Oberbauer, S. Hastings, Appl. Phys. B 102, 391 (2011)

8. E.S.F. Berman, M. Fladeland, J. Liem, R. Kolyer, M. Gupta, Sensors Actuators B Chem. 169, 128 (2012)

9. B. van Well, S. Murray, J. Hodgkinson, R. Pride, R. Strzoda, G. Gibson, M. Padgett, J. Opt. A. Pure Appl. Opt. 7, S420 (2005)

10. M.B. Frish, R.T. Wainner, M.C. Laderer, M.G. Allen, J. Rutherford, P. Wehnert, S. Dey, J. Gilchrist, R. Corbi, D. Picciaia, P. Andreussi, D. Furry, in Proc. SPIE 8726, Next-Generation Spectrosc. Technol. VI, ed. by M.A. Druy, R.A. Crocombe (2013), p. 87260C

11. T. Gardiner, M.I. Mead, S. Garcelon, R. Robinson, N. Swann, G.M. Hansford, P.T. Woods, R.L. Jones, Rev. Sci. Instrum. 81, $83102(2010)$

12. A. Khan, D. Schaefer, L. Tao, D.J. Miller, K. Sun, M.A. Zondlo, W.A. Harrison, B. Roscoe, D.J. Lary, Remote Sens. 4, 1355 (2012)

13. C.R. Webster, P.R. Mahaffy, S.K. Atreya, G.J. Flesch, K.A. Farley, The MSL Science Team, Science 342, 355 (2013)

14. P.R. Mahaffy, C.R. Webster, M. Cabane, P.G. Conrad, P. Coll, S.K. Atreya, R. Arvey, M. Barciniak, M. Benna, L. Bleacher, W.B. Brinckerhoff, J.L. Eigenbrode, D. Carignan, M. Cascia, R.A. Chalmers, J.P. Dworkin, T. Errigo, P. Everson, H. Franz, R. Farley, S. Feng, G. Frazier, C. Freissinet, D.P. Glavin, D.N. 
Harpold, D. Hawk, V. Holmes, C.S. Johnson, A. Jones, P. Jordan, J. Kellogg, J. Lewis, E. Lyness, C.A. Malespin, D.K. Martin, J. Maurer, A.C. McAdam, D. McLennan, T.J. Nolan, M. Noriega, A.A. Pavlov, B. Prats, E. Raaen, O. Sheinman, D. Sheppard, J. Smith, J.C. Stern, F. Tan, M. Trainer, D.W. Ming, R.V. Morris, J. Jones, C. Gundersen, A. Steele, J. Wray, O. Botta, L.A. Leshin, T. Owen, S. Battel, B.M. Jakosky, H. Manning, S. Squyres, R. Navarro-González, C.P. McKay, F. Raulin, R. Sternberg, A. Buch, P. Sorensen, R. Kline-Schoder, D. Coscia, C. Szopa, S. Teinturier, C. Baffes, J. Feldman, G. Flesch, S. Forouhar, R. Garcia, D. Keymeulen, S. Woodward, B.P. Block, K. Arnett, R. Miller, C. Edmonson, S. Gorevan, E. Mumm, Space Sci. Rev. 170, 401 (2012)

15. J. Stieger, I. Bamberger, N. Buchmann, W. Eugster, Atmos. Chem. Phys. 15, 14055 (2015)

16. O.T. Denmead, M.R. Raupach, F.X. Dunin, H.A. Cleugh, R. Leuning, Glob. Chang. Biol. 2, 255 (1996)

17. D. Herriott, H. Kogelnik, R. Kompfner, Appl. Opt. 3, 523 (1964)

18. L.S. Rothman, I.E. Gordon, Y. Babikov, A. Barbe, D. Chris Benner, P.F. Bernath, M. Birk, L. Bizzocchi, V. Boudon, L.R. Brown, A. Campargue, K. Chance, E.A. Cohen, L.H. Coudert, V.M. Devi, B.J. Drouin, A. Fayt, J.-M. Flaud, R.R. Gamache, J.J. Harrison, J.-M. Hartmann, C. Hill, J.T. Hodges, D. Jacquemart, A. Jolly, J. Lamouroux, R.J. Le Roy, G. Li, D.A. Long, O.M. Lyulin, C.J. Mackie, S.T. Massie, S. Mikhailenko, H.S.P. Müller, O.V. Naumenko, A.V. Nikitin, J. Orphal, V. Perevalov, A. Perrin, E.R. Polovtseva, C. Richard, M.A.H. Smith, E. Starikova, K. Sung, S. Tashkun, J. Tennyson, G.C. Toon, V.G. Tyuterev, G. Wagner, J. Quant. Spectrosc. Radiat. Transf. 130, 4 (2013)
19. K. Sun, L. Tao, D.J. Miller, M.A. Khan, M.A. Zondlo, Appl. Phys. B 110, 213 (2013)

20. D.J. Miller, K. Sun, L. Tao, M.A. Khan, M.A. Zondlo, Atmos. Meas. Tech. 7, 81 (2014)

21. A. Klein, O. Witzel, V. Ebert, Sensors 14, 21497 (2014)

22. B. Wolf, C. Chwala, B. Fersch, J. Garvelmann, W. Junkermann, M.J. Zeeman, A. Angerer, B. Adler, C. Beck, C. Brosy, P. Brugger, S. Emeis, M. Dannenmann, F. De Roo, E. Diaz-Pines, E. Haas, M. Hagen, I. Hajnsek, J. Jacobeit, T. Jagdhuber, N. Kalthoff, R. Kiese, H. Kunstmann, O. Kosak, R. Krieg, C. Malchow, M. Mauder, R. Merz, C. Notarnicola, A. Philipp, W. Reif, S. Reineke, T. Rödiger, N. Ruehr, K. Schäfer, M. Schrön, A. Senatore, H. Shupe, I. Völksch, C. Wanninger, S. Zacharias, H.P. Schmid, Bull. Am. Meteorol. Soc. (2016) (in press)

23. S. Zacharias, H. Bogena, L. Samaniego, M. Mauder, R. Fuß, T. Pütz, M. Frenzel, M. Schwank, C. Baessler, K. Butterbach-Bahl, O. Bens, E. Borg, A. Brauer, P. Dietrich, I. Hajnsek, G. Helle, R. Kiese, H. Kunstmann, S. Klotz, J.C. Munch, H. Papen, E. Priesack, H.P. Schmid, R. Steinbrecher, U. Rosenbaum, G. Teutsch, H. Vereecken, Vadose Zo. J. 10, 955 (2011)

24. K. Schäfer, M. Zeeman, C. Brosy, C. Münkel, B. Fersch, M. Mauder, and S. Emeis, in Proc. SPIE 10001, Remote Sens. Clouds Atmos. XXI, ed. by A. Comerón, E.I. Kassianov, K. Schäfer (SPIE, Bellingham, WA, USA, 2016), pp. 1000103-1-1000103-9

25. P. Werle, Appl. Phys. B 102, 313 (2011)

26. R.M. Banta, R.K. Newsom, J.K. Lundquist, Y.L. Pichugina, R.L. Coulter, L. Mahrt, Boundary-Layer Meteorol. 105, 221 (2002) 